University of Nebraska - Lincoln

DigitalCommons@University of Nebraska - Lincoln

Congreso internacional sobre iconografía

precolombina, Barcelona 2019. Actas.

$8-20-2020$

De quimeras y transformaciones: Arqueología del arte y figuras polisémicas en los Andes del sur

Inés Gordillo Besalú

Follow this and additional works at: https://digitalcommons.unl.edu/actas2019

Part of the American Material Culture Commons, Indigenous Studies Commons, Museum Studies Commons, Other History of Art, Architecture, and Archaeology Commons, and the Other Languages, Societies, and Cultures Commons

This Article is brought to you for free and open access by the Zea E-Books at DigitalCommons@University of Nebraska - Lincoln. It has been accepted for inclusion in Congreso internacional sobre iconografía precolombina, Barcelona 2019. Actas. by an authorized administrator of DigitalCommons@University of Nebraska - Lincoln. 


\title{
De quimeras y transformaciones: Arqueología del arte y figuras polisémicas en los Andes del sur
}

\author{
Inés Gordillo Besalú
}

Instituto de Arqueología, Facultad de Filosofía y Letras, Universidad de Buenos Aires. ibesalu@gmail.com

\begin{abstract}
Resumen
La propuesta de este trabajo es abordar al universo iconográfico de las sociedades Aguada (Noroeste argentino) enfocando particularmente el análisis de las figuras compuestas y ambiguas. La idea es identificarlas, interpretarlas perceptualmente y caracterizarlas, para luego acceder a otros planos de significación que trascienden el diseño, los que parecen vincularse fuertemente al fenómeno de transformación humano-felínica.
\end{abstract}

Palabras clave: Noroeste argentino precolombino, Iconografía Aguada, Recursos compositivos, Motivos compuestos, Figuras ambiguas.

\begin{abstract}
The proposal of this work is to address the iconographic universe of Aguada societies (Argentine Northwest), focusing particularly on the analysis of compound and ambiguous figures. The idea is to identify them, interpret them perceptually and characterize them, and then access other planes of significance that transcend design, which seem to be strongly linked to the phenomenon of human-feline transformation.
\end{abstract}

Keywords: Pre-Columbian Argentine Northwest, Aguada Iconography, Compositional Resources, Composite Motives, Ambiguous Figures

\section{Introducción}

El Noroeste argentino (Área Andina Meridional) fue escenario de un largo proceso social, con una significativa diversidad de paisajes culturales que se sucedieron en el tiempo y en el espacio. En este marco, fueron factores decisivos la considerable movilidad y el intercambio entre poblaciones que, desde épocas muy antiguas, permitió la circulación de recursos, bienes, saberes e ideas a través de los variados ámbitos propios (los valles del sur, la Puna y su borde de quebradas, los bosques orientales, etc.) y otros aledaños (el Norte de Chile, la costa del Pacífico, las llanuras del Este, etc.)

A lo largo de miles de años se sucedieron y coexistieron sociedades de cazadores- recolectores, pastores y agricultores con distintos modos de vida. En épocas tardías, durante un breve lapso (1470-1536 d.C.) la región se incorporó al Estado Inca o Tawantinsuyo. Luego, con la conquista hispana comienza el final de la historia precolombina. En esta porción del mundo andino, con más de un siglo de resistencias, la presencia europea hubo de instalarse definitivamente tras el sofocamiento de los últimos alzamientos indígenas.

Dentro de esta larga historia, hacia el siglo VII se define aquello que Alberto Rex González llamó, en los años

Publicado en Congreso internacional sobre iconografía precolombina, Barcelona 2019. Actas, Victòria Solanilla Demestre, editora (Lincoln, Nebraska: Zea Books, 2020). https://doi.org/10.32873/unl.dc.zea.1256 


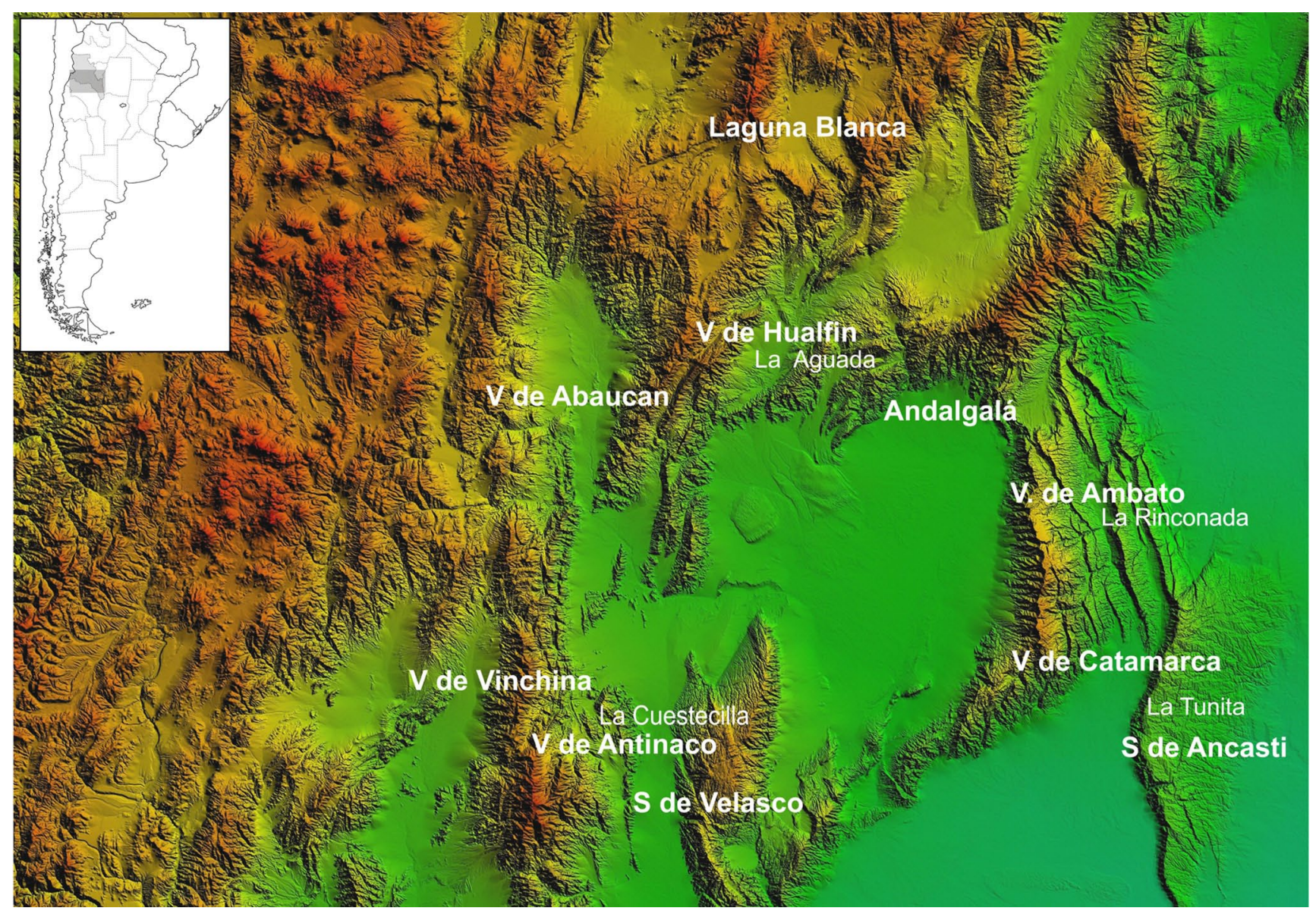

Figura 1: Foto satelital de un sector del Noroeste argentino con los principales sitios de ocupación Aguada (tomada de Gordillo 2018).

60, la "cultura de La Aguada"1 (González 1961-64). Nuestra imagen sobre ese fenómeno se ha conformado en torno a un conjunto de manifestaciones artísticas cuyo particular discurso iconográfico prioriza figuras de jaguares, humanos y seres imaginarios, ejecutadas con maestría en objetos y cuevas.

Sus creadores habitaron la región valliserrana meridional del Noroeste argentino (NOA) (figura 1), durante varios siglos a partir del 600 d.C., tiempos que han sido denominados alternativamente en las periodizaciones construidas para el área como Período Medio (González 1961-64), Formativo Medio (Nuñez Regueiro 1974), Formativo Superior o Floreciente Regional (Raffino 1988) y Período de Integración Regional (Nuñez Regueiro y Tartusi 1990; Pérez Gollán y Heredia 1990).
Según distintos autores (Pérez Gollán y Heredia 1990, González 1998, Cruz 2006, Laguens 2006, etc.), con estos grupos sociales existió un incremento de la población, con un patrón de instalación más complejo y heterogéneo, un perfil novedoso en la explotación o manejo de los recursos agrícola-ganaderos, la especialización y estandarización de bienes materiales, la incorporación de nuevas técnicas, materias y modos constructivos, junto con la arquitectura pública y el despliegue de un arte muy elaborado centrado en la imagen felínica, que se expresa en una variedad de materias y lugares. Todos estos elementos, en conjunto, definen un orden sociocultural que en muchos lugares, bien avanzado el primer milenio de la Era, marcan diferencias con los modos de vida precedentes, pero cuya naturaleza es hoy objeto de discusión.

1. La falta de homogeneidad de sus restos, su ausencia en áreas significativas y a veces su indiferenciación o continuidad con los grupos y procesos sociales previos o paralelos, llevan a algunos autores a cuestionar incluso su condición de cultura y su asociación con un período definido dentro los procesos sociales reconocidos en el NOA. 
Como ya mencioné, su expresión más ampliamente conocida -y tal vez la de más peso a la hora de su reconocimiento- ha sido su particular iconografía. Es en este momento cuando la imagen del jaguar alcanza su máxima expresión a través de diversas técnicas y diseños mobiliarios (cerámica grabada, pintada y modelada, placas de metal, objetos de hueso, etc.) así como en las representaciones rupestres. En todas las modalidades del discurso visual Aguada, cualquier motivo es factible de felinización a través de la representación de garras, manchas u otras porciones anatómicas, las que a su vez se constituyen con frecuencia como elementos metonímicos del jaguar.

Sin embargo, no se trata solo de esa figura, sino particularmente de su combinación con las representaciones humanas y con otros referentes, formando con frecuencia seres imaginarios o quiméricos. En los soportes rocosos, muchas de estas representaciones se reúnen en escenas rituales.

Para esa época, muchas de tales representaciones de carácter ritual y mítico son comunes en las diversas poblaciones de la región. Estos íconos atraviesan su campo expresivo, dando cuenta así de ese contacto activo entre las mismas y del uso de un capital simbólico común al interior de cada una de ellas (Gordillo 2009).

\section{Iconografía Aguada}

En el arte Aguada predomina la figuración ${ }^{2}$. En su mayoría son representaciones que responden a una tentativa de aprehensión de las formas externas y permiten reconocer -parcial o totalmente- elementos del mundo objetivo, definiendo relaciones de semejanza con el objeto referente.

Para caracterizar el discurso visual Aguada, y más allá de las representaciones escénicas o composiciones complejas que reúnen varias figuras, mi interés aquí se centra en el análisis de los motivos, es decir de la unidad gráfica/conceptual del discurso visual (Gordillo 2014a). Los motivos se constituyen entonces como componentes básicos del contenido formal/semántico del diseño y por ello ofrecen amplias posibilidades de análisis y sistematización para el reconocimiento de las lógicas de representación que organizan el discurso visual.

Dentro del repertorio de motivos centro la mirada en cuestiones de composición, morfología y analogía que permiten agruparlos en distintas categorías, considerando en principio a la existencia de un correlato morfológico reconocible con elementos del mundo físico que define al conjunto figurativo de las representaciones. Tales imágenes pueden ser de carácter realista, cuando recrean modelos de existencia física, o bien de carácter fantástico o quimérico, cuando se trata de creaciones imaginarias que combinan elementos reales.

Cabe considerar entonces cuáles son los referentes del mundo físico que se seleccionan para representar. En otras oportunidades he definido los repertorios figurativos del estilo Aguada (Gordillo 2009), intentando reconocer los modelos referentes de cada motivo o significante a partir, como dije, de relaciones de semejanza formal (tabla 1).

Los motivos figurativos realistas son íconos que representan en forma "completa" al modelo o bien aluden a él a través de sus partes componentes o asociadas, a manera de índices (Peirce 1894). Estos últimos, entre los que incluimos los dibujos de manchas, garras, picos, fauces o huellas, actúan por sustitución metonímica a partir de relaciones de causalidad, procedencia o sucesión que establecen con el objeto referente (Gordillo y Basile 2019).

Más allá de la identificación y clasificación de los modelos o referentes, al considerar el modo o forma de representación, los motivos pueden definirse por su configuración simple o compuesta (Kusch 1991). Los primeros hacen referencia a una sola especie o categoría de modelos objetivos, sin combinaciones o agregados de segmentos corporales. Por el contrario, los motivos compuestos reúnen en una sola imagen atributos inter o intra-especie. Esta categoría de motivos corresponde generalmente a figuras de carácter fantástico o imaginario aunque en ocasiones pueden recrear o aludir a modelos reales, constituyéndose como representaciones visuales de representaciones fácticas. Es el caso, por ejemplo, del "enmascarado" de Aguada, motivo por demás frecuente en ese estilo, que representa a un personaje disfrazado de felino (H-F), el que seguramente tuvo una existencia real en las prácticas rituales de esas sociedades.

Así, considerando los estudios iconográficos que anteceden a este trabajo y la reciente revisión sobre el tema realizada sobre una muestra de 219 motivos Aguada

2. Si bien estas categorías resultan operativas para el análisis, los límites precisos entre la figuración y la no-figuración son con frecuencia arbitrarios y es difícil establecer si existe una diferencia de esencia o de grado entre ambas categorías, aspecto que desconocemos debido a la distancia semántica y temporal que nos separan de aquel. 


\begin{tabular}{|c|c|c|c|c|c|}
\hline \multicolumn{3}{|c|}{ MOTIVOS } & \multirow{2}{*}{$\begin{array}{c}\text { Grabados } \\
23,21\end{array}$} & \multirow{2}{*}{$\frac{\text { Pintados }}{3,57}$} & \multirow{2}{*}{$\begin{array}{l}\text { Total } \\
26,78 \\
\end{array}$} \\
\hline \multirow{6}{*}{$\begin{array}{l}\text { simples } \\
52,37 \%\end{array}$} & \multirow{7}{*}{$\begin{array}{c}\text { realistas } \\
61,89 \%\end{array}$} & Felino (F) & & & \\
\hline & & Humano $(\mathrm{H})$ & 11,90 & 5,36 & 17,26 \\
\hline & & Ofidio $(O)$ & 2,38 & 1,19 & 3,57 \\
\hline & & Ave (Or) & 1,78 & 0,60 & 2,38 \\
\hline & & Saurio (S) & 1,19 & - & 1,19 \\
\hline & & Huellas felino (hf) & 1,19 & - & 1,19 \\
\hline \multirow{7}{*}{$\begin{array}{c}\text { compuestos } \\
47,62 \%\end{array}$} & & Felino-humano (HF) & 9,52 & - & 9,52 \\
\hline & \multirow{6}{*}{$\begin{array}{c}\text { fantásticos } \\
38,10 \%\end{array}$} & Felino-felino (FF) & 19,05 & - & 19,05 \\
\hline & & Felino-ofidio (FO) & 4,16 & 2,98 & 7,14 \\
\hline & & Ofidio-ofidio (OO) & 1,19 & 0,60 & 1,79 \\
\hline & & Felino-zoomorfos (FZ) & 6,55 & 1,19 & 7,74 \\
\hline & & Felino-ave (FOr) & 1,19 & - & 1,19 \\
\hline & & Felino-hombre-ave (FHOr) & 1,19 & - & 1,19 \\
\hline \multicolumn{3}{|c|}{ Total } & 84,52 & 15,48 & 100 \\
\hline
\end{tabular}

Tabla 1: Frecuencias de los motivos figurativos en la muestra de cerámica de Aguada de Ambato y sus las técnicas de ejecución asociadas, agrupados según las categorías definidas.

(Gordillo y Basile 2019), revelan en principio un neto predominio de los motivos figurativos $(76,71 \%)$ entre los cuales se definen básicamente tres grupos de motivos (tabla 1 y figura 2) en función de las categorías antes mencionadas:

1) realistas y simples: representación de un referente fáctico.

2) realistas compuestas: representación (o metarepresentación) de un referente fáctico combinado.

3) fantásticos y compuestos: representación combinada de referentes fácticos en uno ficticio.

De esta manera, cualquier motivo realista puede adquirir carácter fantástico o imaginario al integrar elementos derivados del mismo u otro tipo de motivos. En general, los componentes que se aíslan y combinan de cada figura compuesta tienden a mantener las cualidades compositivas que la definen en su forma simple, aspecto que ya fue señalado por Kusch (1991) en su análisis general de la iconografía Aguada. Es decir, lo que se combina no son los modelos sino la forma en que los mismos se representan, por lo cual resulta sustancial abordar el patrón de representación que rige la clase de motivos simples.

Con esa idea, para definir el patrón de representación y acceder a aspectos más estructurales y conceptuales del diseño, he considerado particularmente los "atributos de composición” (sensu Gordillo 2009). Los mismos están referidos a la vista (frontal, perfil, aérea, etc.), la orientación (vertical, horizontal, oblicua, etc.) y la actitud o postura (erguida, sentada, supina, etc.), junto con su distribución dentro del campo decorativo (central, lateral, sucesiva, etc.) y las posibilidades combinatorias recurrentes para formar motivos compuestos (humano-felino, humanoave, felino-ofidio, felino-felino, etc.) (tabla 2).

En este marco, cobran especial importancia los procedimientos compositivos empleados en la construcción de las figuras compuestas o combinadas, que constituyen casi la mitad de la muestra. Al respecto, siguiendo la analítica propuesta en estudios previos (Gordillo 2009 y 2014b), los mismos pueden ordenarse en función de los siguientes modos de combinar: 

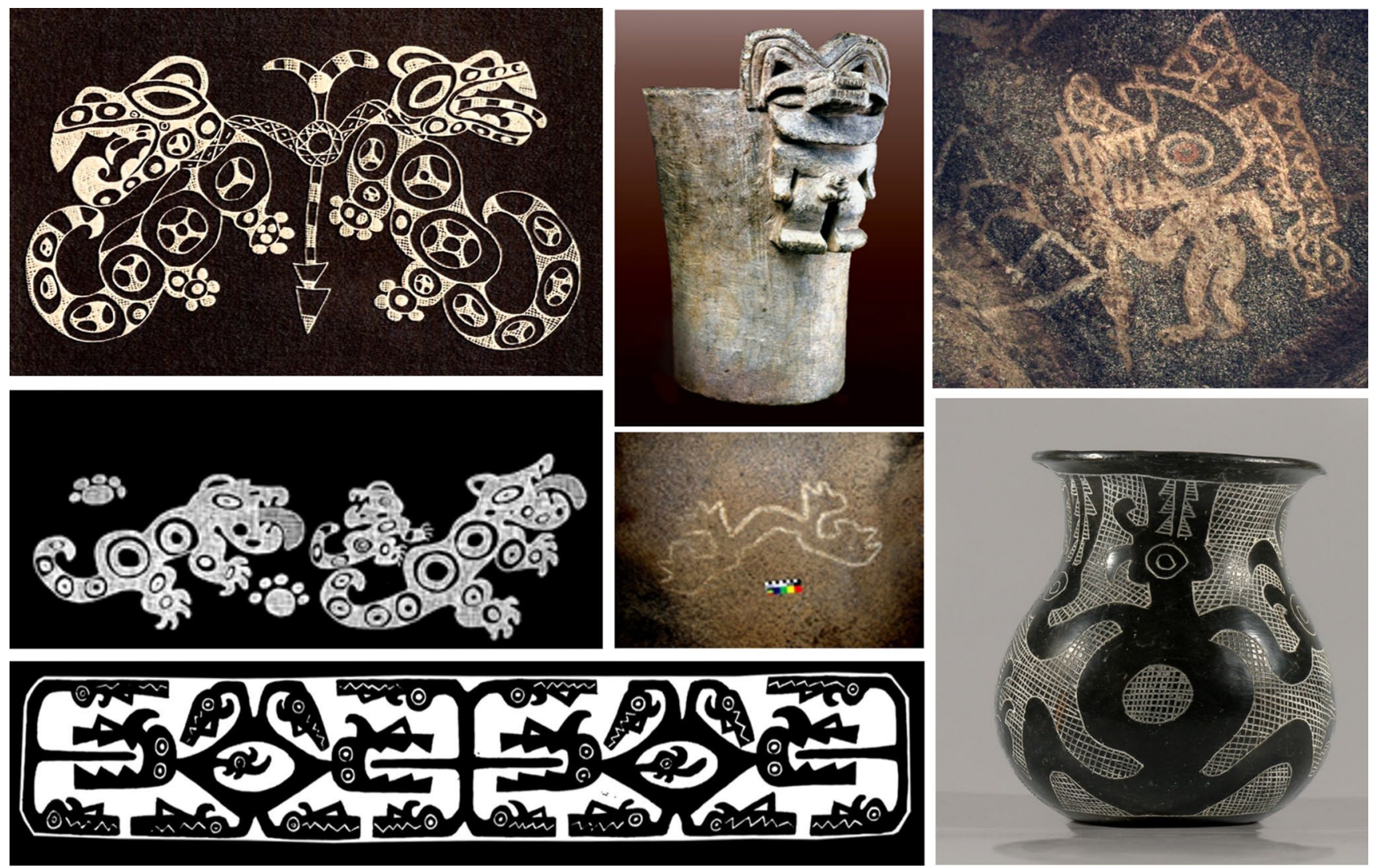

Figura 2: Arriba izquierda: representación realista-simpe de jaguares amarrados (basado en un dibujo de González 1977) y andando (colección A. Rosso, dibujo de la autora). Arriba derecha: la figura del enmascarado (realista-compuesta) tallada en un vaso piedra de $30 \mathrm{~cm}$ de alto, del valle de Catamarca (foto de la autora) y pintado en La Sixtina, La Tunita (Ancasti, Catamarca) (foto de la autora). Centro: figura anatrópica pintada en la cueva de La Toma (Ancasti, Catamarca) (foto autora). Abajo: a la izquierda un diseño fantástico grabado sobre una vasija negra grabada de Ambato, Catamarca (dibujo de a autora) y la derecha, vasija negra de Ambato grabada con figuras fantásticas en negativo; alto 12. MLP. (foto de María D. Arena)

\begin{tabular}{|c|c|c|c|c|c|c|}
\hline \multirow{2}{*}{$\begin{array}{l}\text { Motivo } \\
\text { Felino }\end{array}$} & \multirow{2}{*}{\begin{tabular}{|l|} 
Vista \\
Perfil
\end{tabular}} & \multirow{2}{*}{\begin{tabular}{|l|} 
Orientación \\
Horizontal
\end{tabular}} & \multirow{2}{*}{\begin{tabular}{|l|} 
Actitud \\
Supina
\end{tabular}} & \multicolumn{2}{|c|}{ Espacios compositivos } & \multirow{2}{*}{$\begin{array}{c}\text { Combinación } \\
\text { FHy FF }\end{array}$} \\
\hline & & & & $X-X$ & & \\
\hline & Perfil & Horizontal & s/patas & $X-X$ & $\underline{X X}-\underline{X X}$ & $\mathrm{FF}, \mathrm{FZ}, \mathrm{FO}$ y $\mathrm{FHOr}$ \\
\hline & Perfil & Oblicua & s/patas & $X-X$ & & $\mathrm{FF}$ \\
\hline & Perfil & Vertical & Sentada & $X-X$ & & $\mathrm{FH}$ y $\mathrm{FF}$ \\
\hline Humano & Frontal & Vertical & Erguida & $s X s-s X s$ & $\underline{X X}-\underline{X X}$ & $\mathrm{FH}$ \\
\hline Ofidio & Aérea & Horizontal & $?$ & $X-X$ & & FO y $O O$ \\
\hline Ave & \begin{tabular}{|l|} 
Frontal- \\
Perfil
\end{tabular} & Vertical & Erguida & & $\underline{X X X X}-\underline{X X X X}$ & FHOr \\
\hline Saurio & Aérea & Vertical & $?$ & $X-X$ & & FS SS \\
\hline
\end{tabular}

Tabla 2: Atributos compositivos, distribución y combinación de los motivos simples en Aguada de Ambato. La X representa el motivo unidad y el subrayado señala la presencia de encuadre (tomado de Gordillo 2009). 
a. Por combinación morfológica de distintos referentes (figura 3, izquierda).

b. Por combinación actitudinal o conceptual, donde el sentido dual o múltiple de la figura se define por la contraposición de atributos formales/ conceptuales, tales como la actitud postural, el gesto, la orientación, la acción, etc. (figura 3, derecha)

c. Por ambigüedad óptica o formal, cuando la figura propone interpretaciones excluyentes durante el acto perceptivo y permite identificar distintos referentes.

\section{Los motivos ambiguos y la idea de transformación}

Me interesa detenerme particularmente en la última de las categorías de motivos compuestos debido a su trascendencia dentro del universo expresivo de estos pueblos. El empleo de la ambigüedad óptica o formal es tal vez el recurso plástico más evocativo de cierto tipo de fenómeno que se constituye como uno de los tres núcleos temáticos de la icnografía Aguada (Gordillo 2009): la transformación humana en otros seres -especialmente el jaguar- a través del consumo de sustancias psicotrópicas.

Como ya he señalado, los motivos compuestos con gran frecuentemente el resultado de la combinación directa de rasgos anatómicos y/o actitudinales, pero también pueden lograrse mediante tretas o juegos visuales más complejos que proponen lecturas múltiples y alternas, un efecto perceptivo que no es inocente ni casual. Hay casos donde la misma forma esconde y, a su vez, revela distintos motivos. Según el recurso compositivo empleado para lograr esa disyuntiva óptica, se distinguen en Aguada las imágenes conocidas como anatrópicas y bipartidas, a las que se suman otras representaciones también alternas que no requieren de rotación ni de simetría espejada.

Estas imágenes conocidas como figuras ambiguas se caracterizan por una particular organización formal que genera un sentido doble o múltiple en su interpretación. Durante la percepción estas interpretaciones se alternan de manera espontánea, no se perciben simultáneamente. En las figuras ambiguas planas, ese efecto se produce en virtud de ciertas condiciones que reúne el dibujo: contornos compartidos, áreas comunes, inversión de planos, rotación, etc. Frecuentemente, la experiencia perceptiva se ve privada de una neta discriminación figura-fondo y de la estabilidad e identidad invariables de la figura. Se trata de procedimientos visuales sofisticados que manipulan deliberadamente los principios de clausura, de contraste y de experiencia (sensu la Gestalt, Ciafardo 2007) para
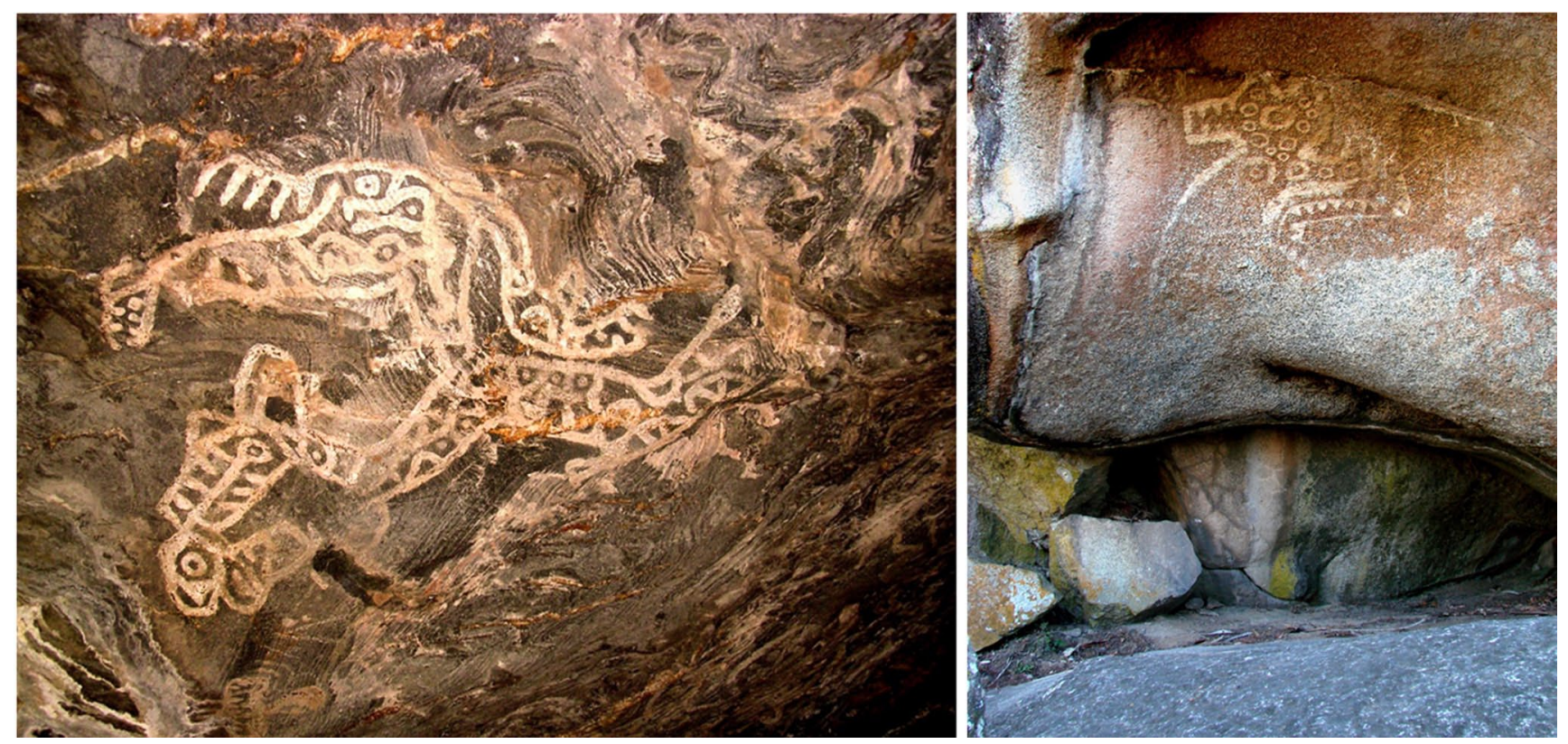

Figura 3: Izquierda: figuras fantásticas felino-ofídicas, cueva La Candelaria (Ancasti, Catamarca). Largo: 112 cm. (foto de la autora). Derecha: felino-humano por combinación actitudinal en La Toma (Ancasti, Catamarca). Alto aproximado de la figura: $140 \mathrm{~cm}$. (foto de Domingo C. Nazar). 

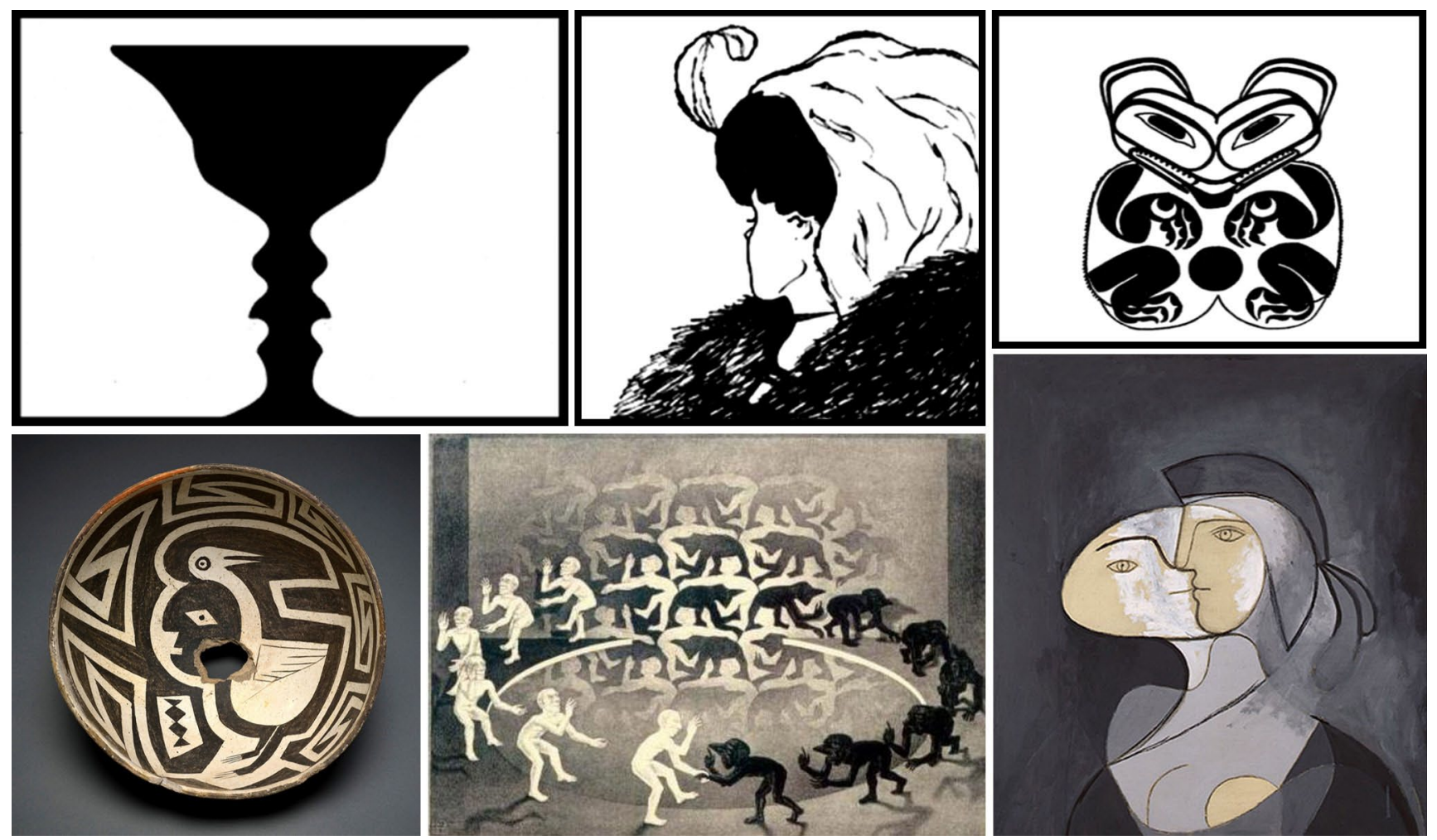

Figura 4: Figuras ambiguas: dos ejemplos de imágenes alternas usados en la teoría de la percepción (Ciafardo 2007), de la cerámica Mimbres del SO de USA (tomado de http://www.centralcalclay.com/mimbres.html) y de un diseño de Escher (tomado se https://www.metmuseum.org/art/collection/search/365239). Las dos figuras de la derecha son bipartidas, del arte tribal de NO de América (Levi-Strauss 1967) y de Picasso (tomado de https://www.pinterest.es/ pin/226587424975007323/).

crear nuevos significados a partir de la ambivalencia y la contradicción.

De esta forma, las imágenes ambiguas muestran muy claramente que el acto perceptivo es una construcción; percibir es discriminar, seleccionar, organizar e interpretar dando sentido. El arte occidental se ha valido de estos recursos en diferentes épocas y autores (v.g. Arcimboldo, Brueghel, Dalí, Ernst, Escher, Magritte, Picasso, entre otros) y las teorías de la percepción los emplean reiteradamente este tipo de imágenes en sus argumentaciones (figura 4).

En la iconografía Aguada las figuras ambiguas comprenden:

- Espejadas (por simetría bilateral): las dos mitades opuestas -referidas a un determinado motivo simple o compuesto- generan, al enfrentarse o adosarse, otra imagen de carácter diferente (Split Representation, sensu Levi Strauss 1967)
- Anatrópicas (por rotación): el carácter ambivalente se manifiesta según la posición en que se observan (González 1974). Girando el diseño, se define otra imagen que reemplaza a la anterior, aun cuando está conformada por los mismos trazos o volúmenes

- Alternas: la ambigüedad se establece por mecanismos de reversibilidad figura-fondo, contornos comunes, cerramientos incompletos, etc. en las expresiones bidimensionales, así como un juego premeditadamente ambivalente de volúmenes en la escultura (Gordillo 2010).

Este conjunto de figuras ambiguas son, reitero, las más ligadas a la idea de la transformación. De hecho son en sí mismas una transformación perceptiva. Por ese motivo retomare aquí algunos casos específicos ${ }^{3}$ que ilustran ese fenómeno en tres tipos diferentes de soporte (rupestre, cerámica y escultura). 


\section{Figura espejada antropo-felínica en soportes rupestres}

En la ladera oriental de la sierra de Ancasti (Catamarca) gran parte de las manifestaciones rupestres de cuevas y aleros se adjudican estilísticamente a Aguada y consisten en figuras antropomorfas, felinos, aves, serpientes y otros motivos, frecuentemente formando escenas. Allí, en la cueva El Guitarrero se destaca una representación de carácter ambiguo, antropo-felínica, configurada por simetría bilateral. Es de gran tamaño, pintada en blanco sobre las superficies grises y rugosas de la roca granítica (figura 5). En el sector superior se definen dos cabezas felínicas de perfil, opuestas y horizontales, con fauces y ojos concéntricos. La figura humana es frontal y simétrica. Se forma por la conjunción de las dos imágenes anteriores. Las cabezas felínicas, opuestas por la nuca, forman el rostro antropomorfo. El espacio de su separación configura la nariz en negativo y los ojos de ambos felinos forman también los humanos. Por debajo, los hombros, brazos, tronco y piernas del personaje. Las manos son -o sostienen- dos cabezas felínicas hacia adentro, invertidas con respecto a las otras, pero con la misma configuración.
En síntesis, puede caracterizarse este diseño como una figura de doble lectura, es decir, que reúne dos interpretaciones perceptuales alternas. Dos motivos, felino y humano, se superponen diacrónicamente en el acto perceptivo, formando cada uno al otro. En términos compositivos y conceptuales, resultan claramente establecidas la unidad del diseño y el dualismo de referencia. Su análisis pone de manifiesto que este personaje antropofelínico, así como otras imágenes similares del arte mobiliar que exhiben el mismo recurso visual (figura 5, abajo), responde a la concepción compositiva generalizada para cada modelo representado: frontalidad/simetría y centradidad para la figura humana (o no-felínica) versus perfil/asimetría y lateralidad para el felino, así como a la tripartición del espacio compositivo típico de Aguada (FHF)

Este diseño se inscribe dentro de esta última categoría y, además, no puede obviarse en este análisis el contexto de tal representación, ligado al ritual y al trance alucinatorio, aspecto este último que se ve reforzado por el efecto de doble percepción logrado mediante el recurso plástico de la ambigüedad y combinación lateralfrontal de figuras, recreando de esta manera singular la magia de la transformación.

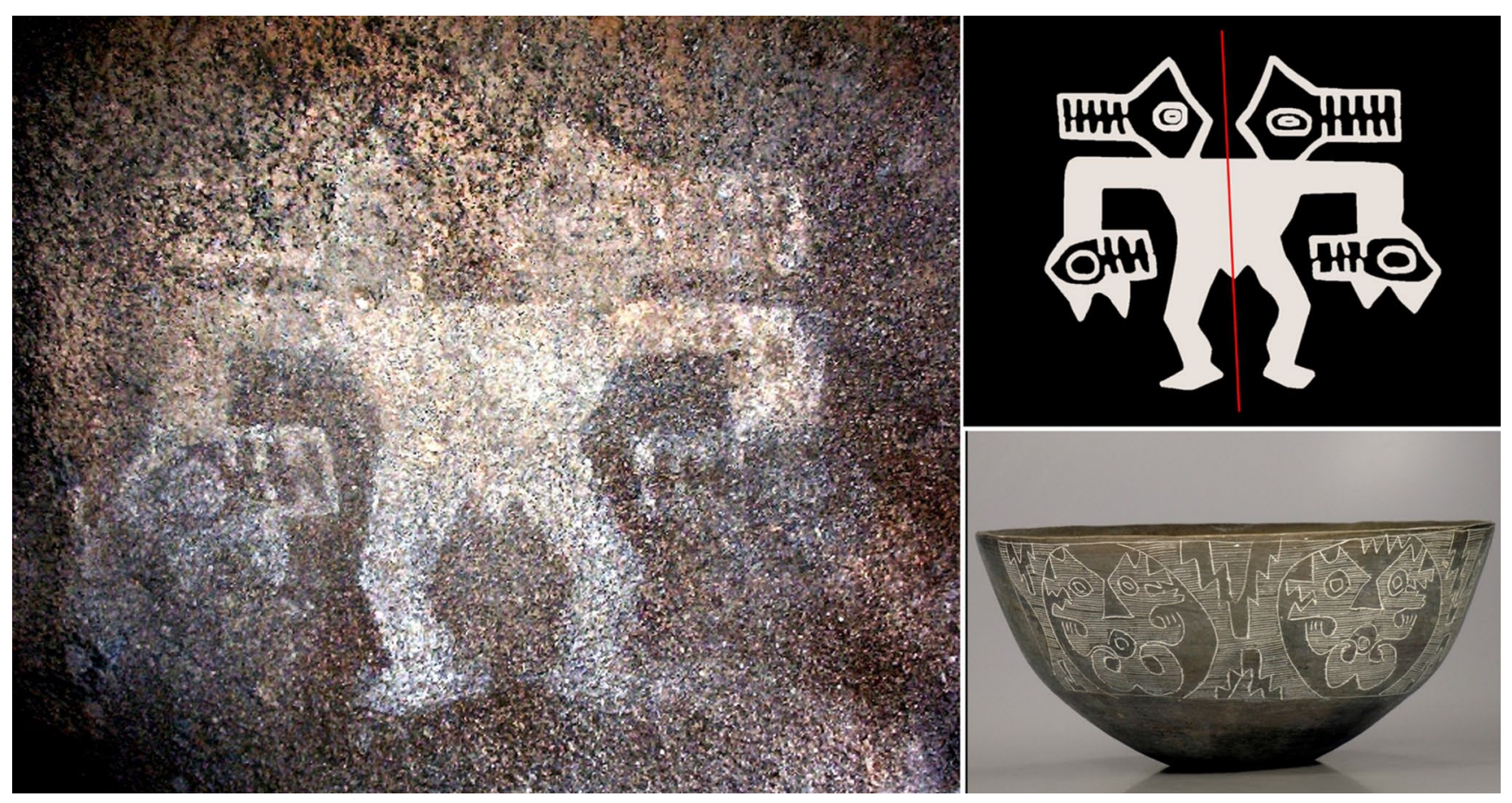

Figura 5: Imagen bipartida humano-felínica, cueva El Guitarrero (Ancasti, Catamarca). Alto: $107 \mathrm{~cm}$. (foto y dibujo de la autora). Abajo derecha: escudilla gris grabada con representaciones bipartidas humano-felínicas, Aguada; alto: 10 cm. Colección Museo de La Plata (foto de María D. Arena) 


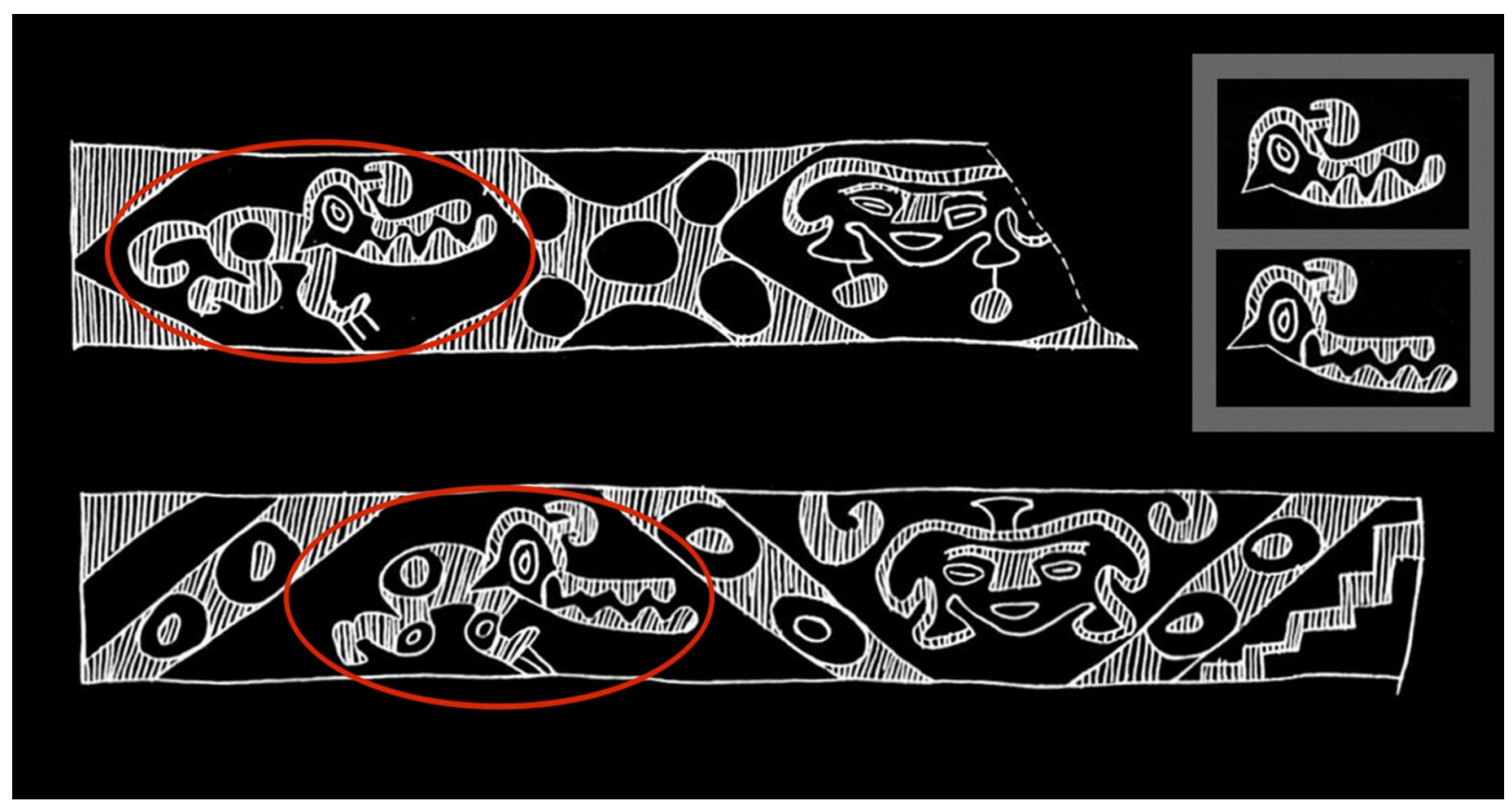

Figura 6: Diseño en bandas de una escudilla negra grabada de La Rinconada, Ambato, Catamarca, con motivos ambiguos humano-felino-ornitomorfo (dibujo de la autora)

\section{Alternancia perceptiva y combinación gestual en soportes cerámicos}

En la iconografía Aguada, la asociación entre figuras humanas, felínicas y ornitomorfas adquiere formas de expresión directas e indirectas. Entre estas últimas, conocemos varios ejemplares del valle de Ambato, como el caso de un diseño grabado en positivo sobre una escudilla negra pulida que fue hallada en una vivienda (E4) del sitio La Rinconada (Gordillo 2009).

La figura ambigua que me interesa destacar se repite en dos bandas horizontales junto con otros elementos figurativos y geométricos (figura 6). Ese motivo compuesto se genera por la que reunión de varios elementos: 1) el componente antropomorfo $(\mathrm{H})$ alude a un cuerpo humano disfrazado y gateando, su identidad resulta más evidente en la forma de los miembros: brazos y manos, piernas y pies; 2) el componente felínico (F) se manifiesta a través de distintos atributos, como las fauces y las manchas de jaguar (el disfraz) y la actitud, postura y orientación del cuerpo; 3) el componente ornitomorfo (Or) se define como una imagen alterna de la cabeza-máscara felínica. La configuración de esta última resulta ser paralelamente un pájaro orientado en sentido inverso: el pico se recorta sobre el torso del personaje, el ojo es el mismo para ambos y las fauces se convierten en las alas del ave. Coexisten aquí dos figuras simultáneas que implican dos interpretaciones temáticas excluyentes en acto perceptivo.

En consecuencia, además de la combinación gestual y formal, concurren en la imagen la alternacia de imágenes a partir de la reversibilidad de las figuras.

Otro diseño notable que se repite en tres ejemplares de la misma zona ${ }^{7}$, consiste en una figura fantástica lograda por la simultaneidad de dos imágenes en una misma forma. La primera interpretación remite al típico felino sentado con manchas en negativo en el cuerpo y cola enroscada. La cabeza muestra grandes fauces abiertas, lengua saliente, ojo redondo con pupila y oreja inclinada sobre el cuerpo. Una segunda lectura permite reconocer que la cabeza felínica es también una cabeza ornitomorfa orientada en sentido opuesto, con un gran pico -la oreja caída del felino- y el ojo compartido (figura 7).

En consecuencia es posible interpretar esta representación como una figura de carácter dual felino-ornitomorfa, a la que se suma el componente humano en la 

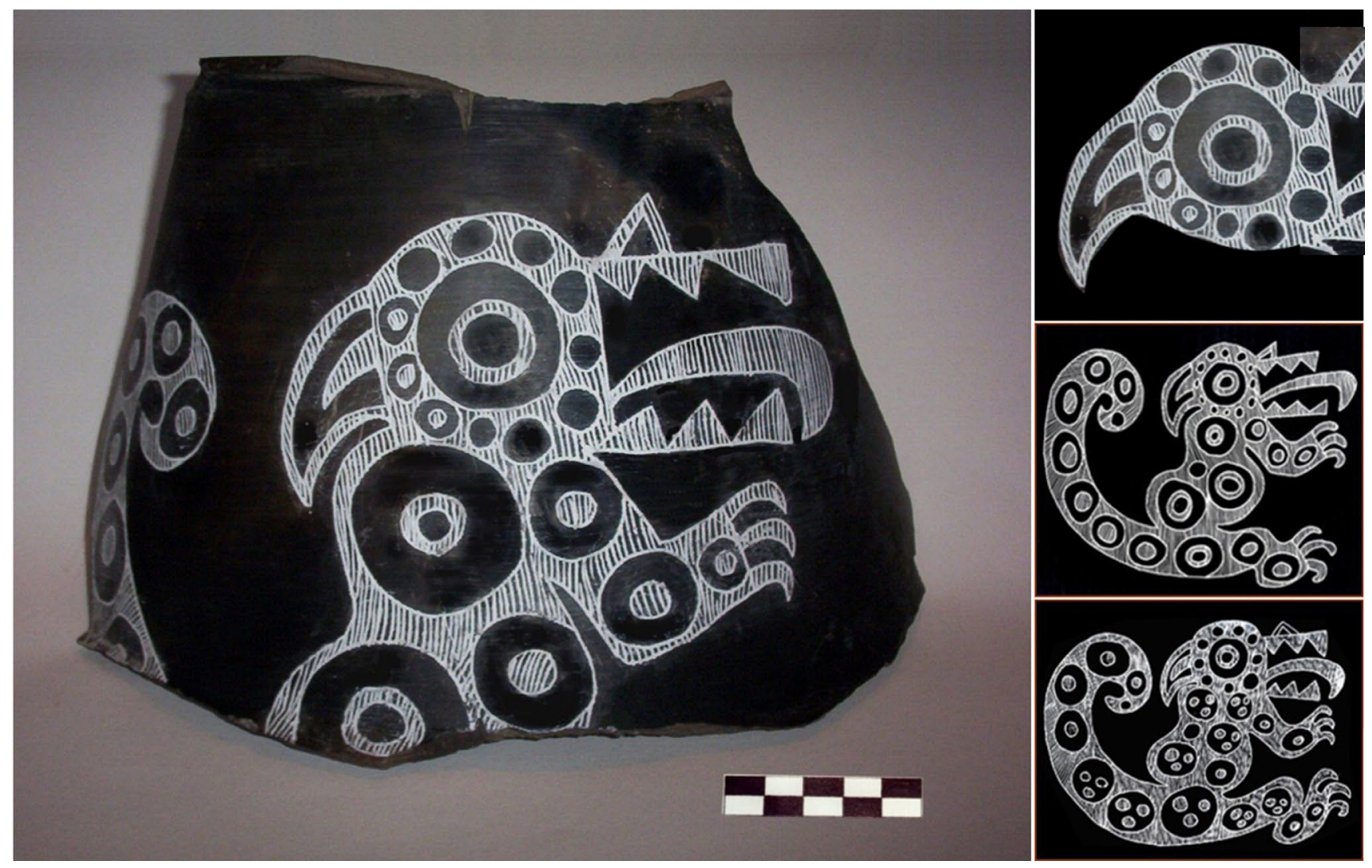

Figura 7: Representación felino-ornitomorfa-humana en un tiesto negro grabado de La Rinconada, Ambato, Catamarca (foto de la autora)

actitud "sentada" del felino. Se define entonces una trilogía que relaciona los mismos términos que el caso anterior.

\section{Formas anatrópicas y alternas talladas en piedra}

Dentro de las colecciones arqueológicas del Museo de La Plata, una de las piezas tallada en un bloque de piedra constituye uno de los más notables ejemplares de la escultura precolombina del Noroeste argentino. Presenta una complejidad técnica, formal y conceptual que, sin duda, es el resultado de un plan cuidadoso. La escultura está concebida como dos imágenes talladas en los extremos de un recipiente rectangular de escasa profundidad y con cuatro soportes o patas (figura 8). Las cabezas de ambas figuras se proyectan a cada extremo del eje principal de la pieza, sobre sus lados menores. Los apoyos del recipiente son al mismo tiempo las patas o piernas de las figuras. Por su cavidad central se define, funcionalmente, como un mortero o fuente, posiblemente para sustancias rituales.
Ambos lados de la pieza representan figuras diádicas, felino-antropomorfa, en uno, y antropo-felínica, en otro. A su vez, los dos sectores de cada figura se oponen a sus homólogos en la otra figura. Para ello se pusieron en juego múltiples de componer la imagen tridimensional; además de la combinación morfológica y actitudinal, se emplearon recursos propios de la ambigüedad anátrópica y alterna.

Así, el sentido ambiguo e intencional de la dualidad se incrementa y se refuerza con la imagen doblemente opuesta del otro extremo de la pieza (figura 8, esquema de oposiciones)

En términos interpretativos es necesario considerar que las figuras antropo-felínicas que se oponen/ enlazan en los extremos aparecen intermediadas por la cavidad central, el segmento destinado a molienda, consumo o depósito de alucinógenos. Todo en el objeto, en cuanto a forma, función y contenido, habla de la transformación. 


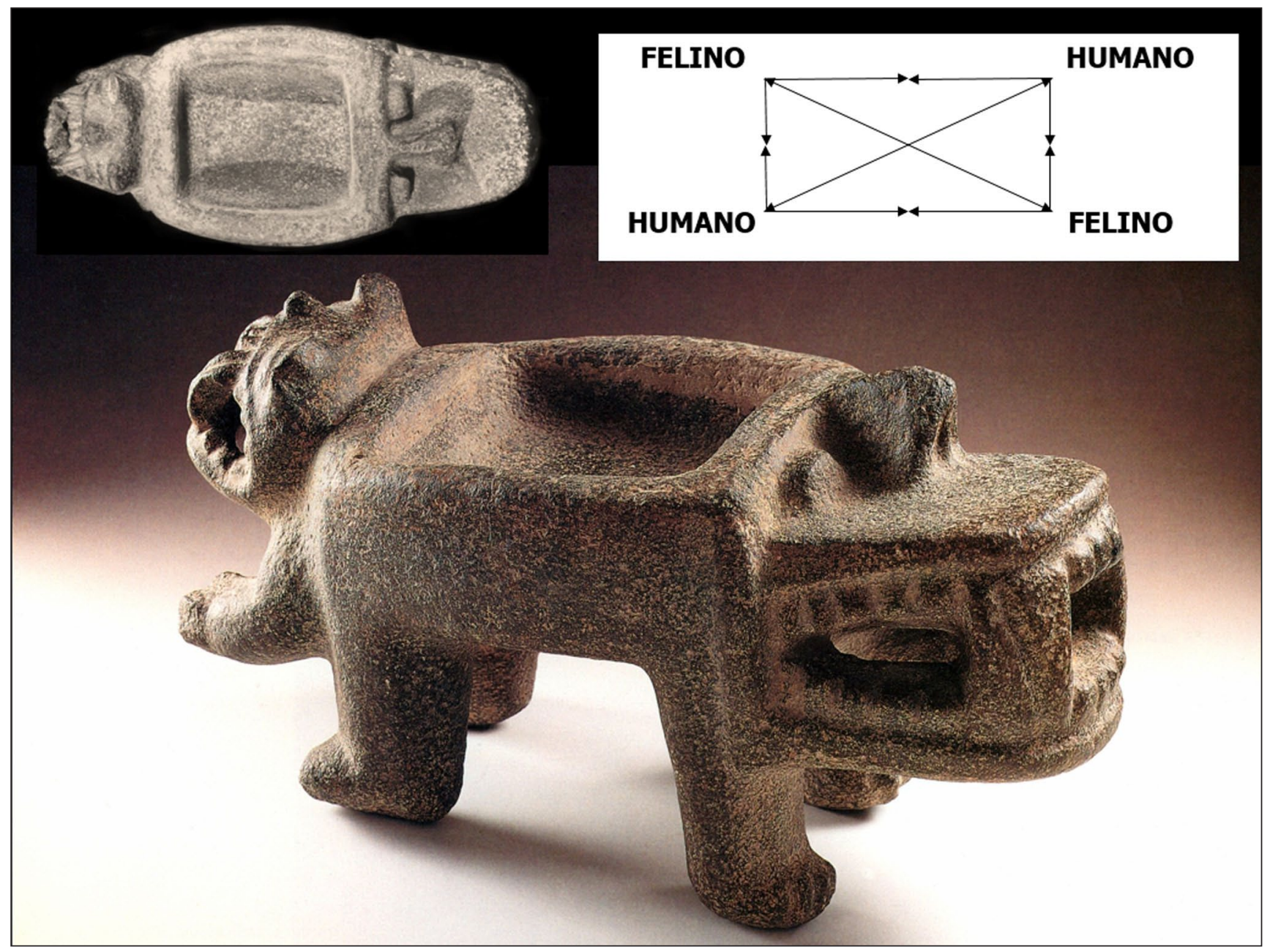

Figura 8: Mortero esculpido con figuras humano-felínicas doblemente opuestas. Vista superior, lateral y esquema del diseño. Colección Museo de La Plata; largo: 47 cm. (fotos tomadas de Gordillo 2010).

\section{A modo de cierre}

Más allá de los referentes reales o imaginarios que expresa la figuración Aguada, la propuesta es trascender lo meramente argumental para alcanzar otro plano de análisis que permita comprender el contenido de esa iconografía a través de su forma.

Los resultados obtenidos hasta el momento en ese terreno apuntan a definir sus principales núcleos o campos temáticos. Estos aluden claramente a las esferas mítica y ritual, constituyendo la expresión visual de una ideología religiosa que se disocia de las prácticas sociales concretas referidas al orden económico (Gordillo 2009)

A juzgar por el repertorio de representaciones, la imagen del mito parece estar fuertemente instaladas en el imaginario colectivo a través de formas animales redundantes como la del jaguar y las figuras quiméricas de seres sobrenaturales.

Paralelamente, la representación del rito remite a dos temas principales: el sacrificio y la transformación. Esta última, encuentra su expresión visual en muchos motivos compuestos, entre ellos -y especialmente- los de carácter ambiguo. En ese sentido, el análisis e interpretación de algunas representaciones permitió reforzar esta hipótesis.

Cabe recordar que esta iconografía se vincula íntimamente, y de varias maneras, a los estados alternos de conciencia. En numerosas sociedades americanas, el empleo de sustancias alucinógenas se encuentra profundamente insertado en el sistema de creencias y prácticas rituales y, con frecuencia, es la llave de acceso al mundo mítico y sobrenatural, habitado por seres con 
morfologías análogas o alternativas a las formas vivientes (Gordillo 1998).

En el Noroeste argentino la vigencia de esa práctica se extiende por más de tres milenios antes de la conquista, con un uso intensivo de plantas psicoactivas, especialmente de vilca o cebil (Anadenanthera colubrina var. cebil). Acorde con esa tradición, las sociedades Aguada asignaron un alto valor a estas sustancias, testimoniado en los numerosos implementos que usaron para su consumo: morteros de piedra, espátulas, tabletas, tubos, pipas, ceramios, entre otros. Muchos de ellos presentan -como vimos- una particular o compleja elaboración formal y conceptual, de carácter ambiguo, como muestra el análisis de la figura grabada sobre cerámica y la tallada en piedra.

En el caso mortero, no podemos obviar que las imágenes humanas y felínicas simbólicamente se oponen y se enlazan asociadas a la cavidad central. Su sentido se refuerza en virtud de ese espacio de alucinógenos, los que constituyen la llave de la transformación y del acceso a lo sobrenatural, permitiendo además la confirmación del mito y las creencias.

Asimismo, son notables las manifestaciones de arte rupestre que sugieren el consumo ritual de alucinógenos, como aquellas imágenes pintadas en las cuevas de la Sierra de Ancasti, emplazadas entre los bosques de cebil. En el caso de la figura espejada de la cueva El Guitarrero -como en otras cuevas y aleros del área- resulta por demás elocuente el contexto socio-ambiental de tal representación. Todo se orienta al ritual y al trance alucinatorio que lo sostiene, aspecto que se ve reforzado por el efecto de doble percepción logrado mediante el recurso plástico de la ambigüedad y combinación lateral-frontal de figuras, recreando de esta manera singular la experiencia de la transformación.

En todos los casos, la iconografía Aguada muestra un potencial semántico no sólo en la elección motivo, sino también en el modo de representarlo y en su ubicación espacial relativa, seguramente más involucrado con su significado y lugar en las estructuras de pensamiento que con los modelos naturales que aquellos evocan. La recurrencia de principios compositivos en el plano de la expresión -que remite sin duda a un contenido simbólico más difícil de aprehender- atraviesa un conjunto amplio de diseños Aguada, desde los que combinan motivos simples o realistas de manera sencilla hasta las más complejas figuras imaginarias o fantásticas. Entre estas últimas, el efecto de doble o múltiple percepción logrado mediante el recurso plástico de la simultaneidad/ alternancia, la combinación lateral-frontal espejada, la reversibilidad figura-fondo y la rotación, recrea y provoca de manera real en el acto perceptivo la magia de la transformación. Quien observa esas figuras, experimenta el trance y la alucinación. Así, esta iconografía se constituye como la expresión plástica de la metamorfosis del hombre en el jaguar mitológico.

\section{Referencias bibliográficas}

CIAFARDO, M. 2007. La Teoría de la Gestalt en el marco del Lenguaje Visual. En: http://lenguajevisual1bfba. wix.com/lenguajevisual1b-fba y www.fba.unlp.edu.ar / apreciacionmusical .

CRUZ, P. 2006. Complejidad y heterogeneidad en los Andes meridionales durante el Período de Integración Regional (siglos IV-X d. C.). Nuevos datos acerca de la arqueología de la cuenca del río de Los Puestos (Dpto. Ambato, Catamarca, Argentina) Bulletin de l'Institut Français d'Études Andines, 35 (2): 121-148.

GONZÁLEZ, A. R. 1961-64. La Cultura de La Aguada del N.O.A. Revista del Instituto de Antropología. Facultad de Filosofía y Humanidades (UNC), Córdoba, Tomo II, pp. 2-21. 1974. Arte, Estructura y Arqueología. Análisis de figuras duales y anatrópicas del Noroeste Argentino. Buenos Aires: Nueva Visión Fichas 35.

- 1977. Arte precolombino en la Argentina: Introducción a su historia cultural. Filmediciones Valero. Buenos Aires. 1998. Cultura de La Aguada; Arqueología y Diseño. Filmediciones Valero. Buenos Aires.

GORDILLO, I. 1998. Del Barro a la figura. Caracterización de la alfarería Aguada de Ambato. En Homenaje a A. $R$. González, 50 años de aportes al desarrollo y consolidación de la Antropología Argentina, FADA, Buenos Aires: FFyL, UBA, pp. 285-308.

- 2009. Dominios y recursos de la imagen. Iconografía cerámica del valle de Ambato (Catamarca, Argentina). Estudios Atacameños, 37:99-121.

— 2010. La Imagen del felino en la América precolombina. Corpus Antiquitatum Americanensium VIII, Academia Nacional de la Historia, Grupo Abierto Libros, Buenos Aires. 2014a. "Motif" in the Archeology of Art. En Encyclopedia of Global Archaeology, C. Smith (ed.) London: Springer New York, Heidelberg, Dordrecht, pp. 5051-5052.

— 2014b. El sentido de lo ambiguo. Imágenes compuestas y alternancia perceptiva en la gráfica Aguada del Noroeste argentino. CONAR I, Rosario, pág. 41, (MS). (Comp.) 2018. Los pueblos de La Aguada. Vida y arte. Academia Nacional de la Historia, Corpus Antiquitatum Americanensium de la Union Académique Internationale 
(Bruselas), Editorial Selectus S. R. L, Buenos Aires. Edición bilingüe español-inglés (con Comité Editorial).

GORDILLO, I. y M. BASILE. 2019. Los unos y los otros: contraposición y reflexiones sobre distintos universos expresivos del NOA prehispánico. Boletín del Museo Chileno de Arte Precolombino, vol.24 no.1, pp. 153-179.

KUSCH M.F. 1991 Forma, diseño y figuración en la cerámica pintada y grabada de la Aguada. En El arte rupestre en la arqueología contemporánea, M. Podestá, Hernández Llosas, M. I. y Renard de Coquet, S. (eds), Buenos Aires: Serie Publicaciones SAA, pp. 14-24.

LAGUENS, A. 2006. Continuidad y ruptura en procesos de diferenciación social en comunidades aldeanas del valle de Ambato, Catamarca, Argentina (s. IV-X dC.). Chungara (Arica), 38, № 2: 211-222.

LEVI STRAUSS, C. 1967. Structural Anthropology. New York: Doubleday.
NUÑEZ REGUEIRO, V. 1974. Conceptos instrumentales y marco teórico en relación al análisis del desarrollo cultural del Noroeste Argentino. Revista del Instituto de Antropología V, Córdoba., pp. 169-190.

NUÑEZ REGUEIRO, V. y M. TARTUSI 1990. Aproximación al estudio del área pedemontana de Sudamérica. Cuadernos. № 12. Instituto Nacional de Antropología. Buenos Aires, pp 130-159.

PÉREZ GOLLÁN Y HEREDIA 1990. Hacia un replanteo de la cultura de La Aguada. Cuadernos №. 12 Instituto Nacional de Antropología, Buenos Aires, pp. 161-179.

PEIRCE, CH. S. 1894. ¿Qué es un signo?, Traducción castellana de Uxia Rivas; 1999. http://www.unav.es/gep/Signo.html RAFFINO, R. 1988. Poblaciones indígenas en Argentina. Ed. TEA, Buenos Aires. 